\title{
Produção e caracterização de briquetes a partir de resíduos sólidos e prensagem semi-manual
}

\author{
Arthur Santos Magalhães ${ }^{1}$ Tiago Miguel Martins da Silva ${ }^{2}$ Vinicius Gomes de Castro ${ }^{2 *}$ \\ ${ }^{1}$ ERA Florestal Ltda. \\ ${ }^{2}$ Universidade Federal Rural do Semi-Árido, R. Francisco Mota, 572 - Pres. Costa e Silva, Mossoró - RN, 59625-900 \\ *Author for correspondence: vinicius.castro@ ufersa.edu.br
}

Received: November 2018 / Accepted: July 2019/ Published: September 2019

\section{Resumo}

No semiárido brasileiro, há uma pressão sobre a vegetação nativa devido a demanda energética local que estimula a busca de alternativas energética, principalmente voltada para população de baixa renda. Este trabalho teve como objetivo produzir briquetes de nove diferentes combinações de cinco tipos de resíduos sólidos: resíduos da madeira de Maçaranduba (Manilkara sp); finos de carvão; e três tipos de resíduos urbanos celulósico (papel para impressão, papelão e papel jornal). Os briquetes foram prensados em equipamento de baixa pressão. Para a caracterização, foram analisadas as propriedades físicas, químicas, o índice de combustão e o poder calorífico. Embora os briquetes tenham apresentado valores de massa específica abaixo do recomendado 0,6 g.cm-3, foi possível identificar tratamentos com altos valores satisfatórios de materiais voláteis, baixo teor de cinzas e alta porcentagem de carbono fixo, características consideradas positivas para briquetes. Briquetes produzidos com a mistura de finos de carvão e serragem, aglomerados com papelão ou papel jornal, apresentaram maiores valores médios de poder calorífico $(33,9$ e 34 MJ.Kg-1, respectivamente) e de índices de combustão adequados $(1,9)$ para uso como fonte de energia.

Palavras-chave: Manilkara sp; Energia; Prensa de Peterson

\section{Abstract}

In the Brazilian semi-arid region, there is a threat to native vegetation duo to the local energy demand that stimulate the search for alternative energy sources, mainly oriented for low-income population. The aim of this work was to produce briquettes using nine different combinations of five solid wastes types: Maçaranduba wood (Manilkara sp); charcoal fine; and three types of cellulosic material (offset paper, cardboard and newsprint paper). Briquettes were pressed by low pressure equipment. The physical and chemical properties, combustion index and heating value were analyzed for the briquettes characterization. Although the briquettes showed specific gravity values lower than recommended $0.6 \mathrm{~g} . \mathrm{cm}-3$, it was possible to indentify treatments with high volatile matters values, low ash contents and high fixed carbon contents, characteristics considered positives for briquettes. The nine types of briquettes had shown potential as energy generators. Briquettes produced with a mixture of wood charcoal fines and sawdust, using cardboard or newsprint paper as binder, showed higher averages of heating value (33.9 and 34 MJ.Kg-1, respectively) and suitable combustion indexes (1.9) for energy sources.

Keywords: Manilkara sp; Energy; Peterson Press

\section{Introdução}

Em um contexto mundial, a intensidade da utilização de madeira como fonte de energia pode ser considerada um indicador do nível de desenvolvimento dos países. Entre os principais produtores de madeira para suprimento de energia no uso doméstico e industrial encontram-se a Etiópia, Brasil e Índia, todos países considerados em desenvolvimento e com taxas média anual de crescimento de produção de $1,64 \%, 0,87 \%$ e $0,59 \%$, respectivamente (Magalhães e Moreira 2011).

No Brasil, esse indicador pode especificamente ser observado ao analisar a matriz energética da região Nordeste. Por exemplo, no Rio Grande do Norte, 24\% do consumo total de energia primária ainda é dependente de lenha e carvão vegetal, com destaque para os setores residencial e industrial, impulsionado principalmente pelas indústrias de cerâmica (Riegelhaupt e Pareyn 2010). Porém, a base energética deste tipo de indústria é insustentável, uma vez que metade de sua demanda vem sendo atendida por lenha de vegetação nativa da caatinga sem plano de manejo (Machado et al. 2010).

No semiárido brasileiro, a pressão sobre a vegetação nativa é um problema ainda mais crítico, pois a regeneração natural em áreas de caatinga é lenta. Desta forma, torna-se necessário buscar formas alternativas para suprir a demanda energética. Uma opção viável é o uso de briquetes produzidos através da compactação de resíduos sólidos, como por exemplo, os finos de carvão vegetal gerados em fornos das indústrias de bioenergia, ou material celulósico descartado, como papel ou papelão com potencial de reciclagem (Martins et al. 2016).

Porém, os equipamentos de compactação dos briquetes podem vir a ser um gargalo para produção dentro de comunidades de baixa rendo por causa do custo com energia elétrica. Desta forma, fez-se necessário o desenvolvimento de tecnologias alternativas voltadas para produção caseira de uma população carente, mas que tem fácil acesso a resíduos. Geralmente, a necessidade de equipamentos mais sofisticados para a fabricação de briquetes está ligada ao uso de alta pressão de compactação (acima de $100 \mathrm{MPa}$ ). Neste caso, a lignina presente no material, devido a suas características químicas, passa a agir como aglomerante do produto (Shy amalee et al. 2015).

Contudo, é possível produzir briquetes com baixa pressão, desde que use um aglomerante na mistura. Tamilvanan (2013) produziu briquetes de diversos resíduos agrícolas prensados manualmente com papel reciclado que agiu como material aglomerante. $\mathrm{O}$ autor considerou que $\mathrm{o}$ uso de apenas de resíduos com uma técnica de prensagem de baixa pressão uma alternativa viável de diminuição da demanda de lenha em comunidades rurais.

$\mathrm{O}$ presente trabalho teve como objetivo produzir e caracterizar briquetes manufaturados com resíduos sólidos e compactados com baixa pressão para suprimento da demanda energética de comunidades com baixo poder aquisitivo no semiárido brasileiro.

\section{Material e métodos}


Magalhães et al.

\section{Coleta e pré-tratamento da matéria-prima}

Dois tipos de resíduos da indústria madeireira foram utilizados como matéria prima para a produção dos briquetes: serragem de madeira e fino de carvão. A serragem foi coletada em uma marcenaria localizada no município de Mossoró, RN, Brasil. A marcenaria foi limpa e o material residual coletado após usinagem de peças de madeira da espécie Manilkara sp. (Maçaranduba), sendo garantido que toda a serragem fosse da espécie. A razão da escolha da madeira foi devido ao fato desta espécie ser a mais comercializada na região supracitada e, assim, gerar o maior volume deste tipo de resíduo (Souza et al. 2018). O fino de carvão foi coletado em carvoarias localizadas no município de Upanema, RN. Os materiais coletados foram processados em moinho de facas e peneirados, sendo empregado apenas os com granulometria menor do que $2 \mathrm{~mm}$.

\section{Coleta e pré-tratamento do material aglutinante}

Foram testados resíduos celulósicos como material aglutinante dos briquetes: papel para impressão, papelão e papel jornal. Coletou-se e separou-se os resíduos no município de Mossoró, RN. O material teve seu tamanho inicialmente reduzido manualmente e retiradas eventuais impurezas (por exemplo, grampos, fitas adesivas). O material foi então submerso em água por um período aproximado de 24 horas. Em seguida, para cada tratamento, o material foi processado com auxílio de liquidificador doméstico. A polpa foi então escorrida em peneira de 16 mesh antes de ser misturada com os resíduos sólidos.

\section{Produção dos briquetes}

Os briquetes foram produzidos em temperatura ambiente e processo de compressão semi-manual de baixa pressão. A densificação ocorreu com o auxílio de uma prensa de Peterson (Figura 1A). Este equipamento utiliza um pistão hidráulico em estrutura feita de madeira. A pressão foi aplicada em um molde de cilíndrico de policloreto de vinila (PVC) com o acionamento do braço do pistão hidráulico (capacidade máxima de carga de $2.000 \mathrm{Kg}$ ). O molde utilizado possuía uma abertura de $45 \mathrm{~mm}$ de diâmetro e altura de $200 \mathrm{~mm}$ que permitiu a produção de briquetes cilíndricos com alturas variando entre 65 e $100 \mathrm{~mm}$ de altura (Figura 1B). Após prensagem de aproximadamente 10 minutos, os briquetes foram retirados e secos ao ar livre por 36 horas.

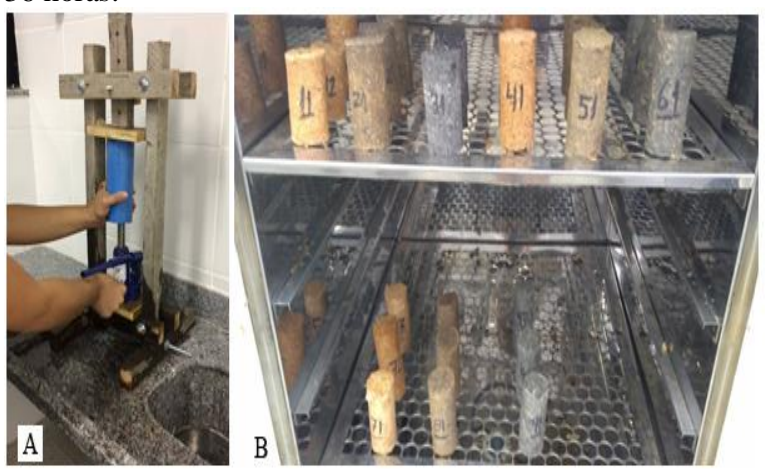

Figura 1. Prensa de Peterson (A) e briquetes cilíndricos produzidos com resíduos sólidos e aglomerantes celulósicos (B).

Os briquetes foram produzidos com uma mistura de $50 \%$ de aglutinante e $50 \%$ de resíduo sólido, com base no peso seco do material. Para cada tipo de aglutinante, além da mistura com serragem e com finos de carvão de forma independente, também foi testado o uso de uma mistura em partes iguais dos dois tipos de resíduos. Ao todo, foram produzidas 3 repetições para cada um dos 9 tratamentos (Tabela 1).

Tabela 1. Proporção da composição dos briquetes em relação ao peso seco das matérias-primas.

\begin{tabular}{|c|c|c|c|c|c|}
\hline \multirow[t]{2}{*}{ Tratamento } & \multicolumn{2}{|c|}{ Resíduo sólido } & \multicolumn{3}{|c|}{ Aglutinante } \\
\hline & Serragem & $\begin{array}{l}\text { Fino de } \\
\text { carvão }\end{array}$ & $\begin{array}{l}\text { Papel de } \\
\text { impressão }\end{array}$ & Papelão & $\begin{array}{l}\text { Papel } \\
\text { jornal }\end{array}$ \\
\hline 1 & $50 \%$ & - & $50 \%$ & - & - \\
\hline 2 & $25 \%$ & $25 \%$ & $50 \%$ & - & - \\
\hline 3 & - & $50 \%$ & $50 \%$ & - & - \\
\hline 4 & $50 \%$ & - & - & $50 \%$ & - \\
\hline 5 & $25 \%$ & $25 \%$ & - & $50 \%$ & - \\
\hline 6 & - & $50 \%$ & - & $50 \%$ & - \\
\hline 7 & $50 \%$ & - & - & - & $50 \%$ \\
\hline 8 & $25 \%$ & $25 \%$ & - & - & $50 \%$ \\
\hline 9 & - & $50 \%$ & - & - & $50 \%$ \\
\hline
\end{tabular}

\section{Caracterização dos briquetes}

A densidade aparente dos briquetes foi determinada pela relação entre a massa e volume do material. O volume foi determinado pelo método estereométrico por imersão e para se evitar absorção de água, os corpos de prova foram previamente envoltos em filme PVC, sendo desconsiderado o seu volume.

Os teores de umidade, materiais voláteis (MV), cinzas e carbono fixo (CF) foram determinados de acordo com a norma adaptada ASTM D 1762-84 (1990). O poder calorífico (PC) dos briquetes foi calculado através dos valores resultantes da química imediata aplicados na fórmula de Gouthal (equação 1) (Fuwape 1996).

$$
P C=2,326 \times[(147,6 \times C F)+(144 \times M V)] \quad(\text { equação } 1)
$$

O teste de combustão foi realizado em um dispositivo de queima de alumínio posicionado sobre uma balança de precisão. Corpos de prova de $50 \mathrm{~mm}$ de altura foram previamente acesos com auxílio de maçarico com aplicação direta da chama por 1 minuto e posicionados no dispositivo de queima. A perda de massa e a temperatura (obtida com um pirômetro) dos corpos de prova foram medidas a cada 5 minutos durante 1 hora. Através destes dados, foi então calculado o índice de combustão (ICOM) (equação 2) (Cruz et al. 2016).

\section{$\mathrm{ICOM}=((\mathrm{A} \times \mathrm{B})) /((100 \times \mathrm{C})) \quad($ equação 2$)$}

Sendo: $\mathrm{A}=$ a porcentagem do tempo em que a temperatura permaneceu acima de $150{ }^{\circ} \mathrm{C} ; \mathrm{B}=\mathrm{a}$ porcentagem da temperatura máxima atingida em relação a temperatura de $150{ }^{\circ} \mathrm{C}$; e $\mathrm{C}=$ a porcentagem da massa total consumida gerando temperaturas acima de $150{ }^{\circ} \mathrm{C}$

$\mathrm{O}$ delineamento experimental foi inteiramente casualizado, com arranjo fatorial para os tratamentos de 
forma a avaliar a interação entre dois fatores: tipos de aglomerante e de resíduo sólido. Uma vez caracterizada a normalidade dos dados pelos testes Skewness e Kurtosis, o efeito dos tratamentos sobre as propriedades dos briquetes foi verificada pela análise de variância (ANOVA). Verificada a existência de diferenças estatísticas entre médias, o teste de Tukey foi aplicado, em nível de probabilidade de $95 \%$, com desdobramento dos fatores para o caso de interação significativa indicada pelo teste $F$ na ANOVA.

\section{Resultados e discussão}

$\mathrm{Na}$ fabricação dos briquetes com prensagem manual, as propriedades físicas (teor de umidade e massa específica) foram influenciadas tanto pela escolha do resíduo sólido usado como matéria-prima, quanto pelo resíduo celulósico usado como aglomerante, assim como a interação destes dois fatores (Tabela 2). Esta influência também foi observada na química imediata dos briquetes, com exceção do teor de cinza que não apresentou influência significativa quanto a interação de fatores.

$\mathrm{O}$ índice de combustão avalia a capacidade do briquete de manter a energia da combustão a partir de sua queima. A Tabela 2 indicou que esta capacidade é influenciada apenas pelo tipo de resíduo sólido utilizado na composição dos briquetes.

Tabela 2. Resumo das análises de variância para as propriedades dos briquetes.

\begin{tabular}{|c|c|c|c|c|c|c|c|c|}
\hline \multirow{2}{*}{ Fator de Variação } & \multirow{2}{*}{$\begin{array}{l}\text { Grau de } \\
\text { Liberdade }\end{array}$} & TU & ME & MV & TC & $\mathrm{CF}$ & $\mathbf{P C}$ & ICOM \\
\hline & & \multicolumn{7}{|c|}{ Quadrado Médio } \\
\hline Aglomerante (A) & 2 & $6,596^{*}$ & $0,054^{*}$ & $116,398^{*}$ & $35,515^{*}$ & $274,533^{*}$ & $4,533^{*}$ & $0,055^{\mathrm{N}:}$ \\
\hline Resíduo Sólido (B) & 2 & $15,71^{*}$ & $0,011^{*}$ & $183,718^{*}$ & $25,237 *$ & $334,191^{*}$ & $3,344 *$ & $0,626^{*}$ \\
\hline$(\mathrm{A} \times \mathrm{B})$ & 4 & $0,235^{*}$ & $0,001^{*}$ & $10,289^{*}$ & $2,136^{\mathrm{NS}}$ & $12,964^{*}$ & $0,256^{\mathrm{NS}}$ & $0,052^{\mathrm{N}:}$ \\
\hline Resíduo & 18 & 0,022 & 0,000 & 0,494 & 1,489 & 2,055 & 0,175 & 0,054 \\
\hline
\end{tabular}

$\mathrm{TU}=$ teor de umidade; $\mathrm{ME}=$ massa específica; $\mathrm{MV}=$ materiais voláteis; $\mathrm{TC}=$ teor de cinzas; $\mathrm{CF}=$ carbono fixo; $\mathrm{PC}=$ poder calorífico; ICOM = índice de combustão; *, Significativo a $5 \%(0,01<\mathrm{p}<0,05)$; ${ }^{\mathrm{NS}}$, Não significativo a $5 \%(\mathrm{p}>0,05)$

Em relação as propriedades físicas dos briquetes foi observada diferença estatística significante entre os valores médios de teor de umidade dos briquetes tanto quando se mudou o resíduo sólido e se utilizou um mesmo aglomerante, quanto se manteve uma mesma matéria-prima, mas se alterou o material aglutinante (Tabela 3). Briquetes produzidos com finos de carvão tendem a apresentar menor teor de umidade do que os produzidos com serragem. Quando as matérias-primas foram misturadas em quantidades iguais, os valores médios foram intermediários aos dos briquetes produzidos apenas com um tipo de material.

Os valores médios de massa específica dos briquetes variaram de $0,33 \mathrm{~g} \mathrm{~cm}^{-3}$ (briquetes de serragem aglutinados com papel jornal) a $0,53 \mathrm{~g} \mathrm{~cm}^{-3}$ (briquetes de finos de carvão aglutinados com papel de impressão). Independente do tipo de aglomerante usado, os briquetes de finos de carvão apresentaram valores médios estatisticamente superiores aos produzidos com serragem. Houve uma correlação entre o tipo de material celulósico usado e a massa específica. Briquetes produzidos com papel de impressão apresentaram valores estatisticamente superior aos demais, e briquetes com papel jornal, valores estatisticamente inferiores.
Tabela 3. Valores médios para as propriedades físicas dos briquetes produzidos com resíduos sólidos e aglomerados com resíduos celulósicos.

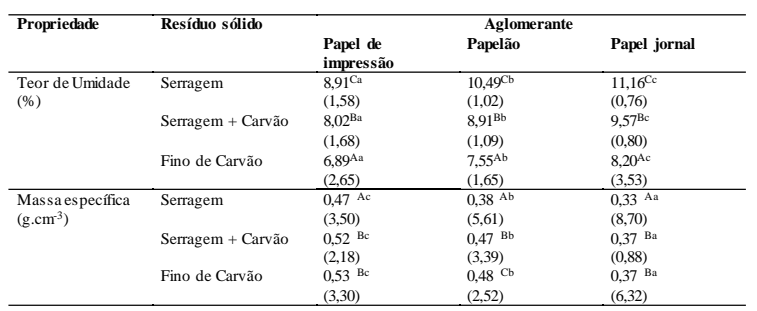

Médias seguidas pela mesma letra maiúscula, na coluna, e minúscula, na linha, não diferem estatisticamente a $5 \%$ de probabilidade pelo teste de Tukey;Valores entre parênteses indicam o coeficiente de variação $(\%)$.

Quando a matéria-prima utilizada foi os finos de carvão, a porcentagem de materiais voláteis foi estatisticamente superior ao dos outros briquetes (Tabela 4). O uso de papel de impressão também gerou valores médios de materiais voláteis superiores do que briquetes formados com o mesmo tipo de resíduo, mas com outro tipo de papel foi utilizado como aglomerante.

O uso de carvão na composição do briquetes também resultou em maiores valores médios de teor de cinzas do que quando o carvão foi misturado com a serragem de Maçaranduba, isso ocorreu para qualquer tipo de aglomerante. Não houve diferença estatística entre os briquetes produzidos só com serragem e aglutinados com qualquer dos três tipos de papel. Para os demais materiais, briquetes com papel de impressão apresentaram valores estatisticamente superior as médias dos briquetes feitos com papelão ou papel jornal.

Os teores médios de carbono fixo foram estatisticamente superiores em briquetes feitos com serragem do que os feitos com finos de carvão. Em relação aos aglomerantes, foi observado que o uso de papel de impressão gerou briquetes com menores valores médios de porcentagem de carbono fixo.

O cálculo do poder calorífico dos briquetes indicou que aqueles produzidos só com finos de carvão apresentaram valores médios estatisticamente inferiores aos produzidos com a mistura entre carvão e serragem. Quando há carvão na composição dos briquetes, o uso de papel de impressão como aglomerante também influenciou negativamente o poder calorífico do produto. Porém, não há diferença entre os valores médios dos briquetes produzidos só com serragem e diferentes tipos de papeis.

Não foi observado um comportamento previsível quando se observou os índices de combustão dos briquetes de resíduos. Quando se utilizou o papel de impressão, os briquetes com a mistura de serragem e carvão apresentaram maior valor médio de ICOM do que os produzidos apenas com serragem. Porém, quando se utiliza o papelão, não se observa essa diferença, mas os briquetes de finos de carvão apresentaram valores superiores aos de serragem. E não houve diferença estatística para os valores de ICOM de diferentes matérias primas quando se utilizou o papel jornal como aglomerante. 
Magalhães et al.

Tabela 4. Valores médios para química imediata e índice de combustão dos briquetes produzidos com resíduos sólidos e aglomerados com resíduos celulósicos.

\begin{tabular}{|c|c|c|c|c|}
\hline Propriedade & Resíduo sólido & $\begin{array}{l}\text { Papel de } \\
\text { impressão }\end{array}$ & $\begin{array}{l}\text { Aglomerante } \\
\text { Papelão }\end{array}$ & Papel jornal \\
\hline \multirow{4}{*}{$\begin{array}{l}\text { Materiais Voláteis } \\
(\%)\end{array}$} & Serragem & & $1,67^{\mathrm{Aa}}$ & $1,76^{\mathrm{Aa}}$ \\
\hline & & $(21,05)$ & $(16,55)$ & $(64,10)$ \\
\hline & Serragem + Carvão & $\begin{array}{l}11,93^{\mathrm{Bb}} \\
(1,86)\end{array}$ & $\begin{array}{l}3,96^{\mathrm{Ba}} \\
(10,27)\end{array}$ & $\begin{array}{l}3,20^{\text {Aa }} \\
(3,17)\end{array}$ \\
\hline & Fino de Carvão & $\begin{array}{l}15,23^{\mathrm{Cc}} \\
(2,23)\end{array}$ & $\begin{array}{l}8,97^{\mathrm{Ca}} \\
(3,73)\end{array}$ & $\begin{array}{l}13,35^{\mathrm{Bb}} \\
(0,35)\end{array}$ \\
\hline \multirow{4}{*}{$\begin{array}{l}\text { Teor de Cinzas } \\
(\%)\end{array}$} & Serragem & $\begin{array}{l}3,93^{\mathrm{Aa}} \\
(50,56\end{array}$ & $2,44^{\mathrm{ABa}}$ & $1,89^{\mathrm{ABa}}$ \\
\hline & Serragem + Carvão & & $\begin{array}{l}(26,91) \\
10^{\text {Aa }}\end{array}$ & $(40,09)$ \\
\hline & & $(31,83)$ & $\begin{array}{l}1,05^{\mathrm{Aa}} \\
3,71 \mathrm{n}\end{array}$ & $\begin{array}{l}0,77^{\mathrm{Aa}} \\
(40,60)\end{array}$ \\
\hline & Fino de Carvão & $\begin{array}{l}8,11^{\mathrm{Bb}} \\
(18,92)\end{array}$ & $\begin{array}{l}4,50^{\mathrm{Ba}} \\
(7.15)\end{array}$ & $\begin{array}{l}3,77^{\mathrm{Ba}} \\
(30,49)\end{array}$ \\
\hline \multirow[t]{5}{*}{ Carbono Fixo (\%) } & Serragem & $88,38^{\mathrm{Ca}}$ & $95,89^{\mathrm{Bb}}$ & $96,34^{\mathrm{Bb}}$ \\
\hline & & $(2,63)$ & $(0,79)$ & $\begin{array}{l}(1,95) \\
960^{\mathrm{Bb}}\end{array}$ \\
\hline & Serragem + Carvão & $82,69^{\mathrm{Ba}}$ & $\begin{array}{l}94,99^{\mathrm{Bb}} \\
(1,57\end{array}$ & $\begin{array}{l}96,03^{\mathrm{Bb}} \\
(0,43)\end{array}$ \\
\hline & Fino de Carvão & $76,64^{\mathrm{Aa}}$ & $86,53^{\mathrm{Ac}}$ & $82,89^{\mathrm{Ab}}$ \\
\hline & & $(2,10)$ & $(0,71)$ & $(1,34)$ \\
\hline \multirow{5}{*}{$\begin{array}{l}\text { Poder calorífico } \\
\left({\left.\mathrm{MJ} . \mathrm{Kg}^{-1}\right)}\right.\end{array}$} & Serragem & $32,92^{\mathrm{Ba}}$ & $33,48^{\mathrm{ABa}}$ & $33,66^{\mathrm{ABa}}$ \\
\hline & & $(2,06)$ & $(0,67)$ & $(0,80)$ \\
\hline & Serragem + Carvão & $32,38^{\mathrm{Ba}}$ & $33,94^{\mathrm{Bb}}$ & $34,04^{\mathrm{Bb}}$ \\
\hline & & $(1,81)$ & & $(0,32)$ \\
\hline & Fino de Carvão & $31,42^{\mathrm{Aa}}$ & $32,71^{\mathrm{Ab}}$ & $32,93^{\mathrm{Ab}}$ \\
\hline \multirow{5}{*}{$\begin{array}{l}\text { Î́ndice de } \\
\text { Combustão }\end{array}$} & Serragem & $\frac{(1,0 \delta)}{1,62^{\mathrm{Aa}}}$ & $1,59^{\mathrm{Aa}}$ & $1,58^{\mathrm{Aa}}$ \\
\hline & & $(11,11)$ & $(16,68)$ & $(23,19)$ \\
\hline & Serragem + Carvão & $2,19^{\mathrm{Ba}}$ & $1,90^{\mathrm{ABa}}$ & $1,81 \mathrm{Aa}$ \\
\hline & & $(1,15)$ & $(13,52)$ & $(5,71)$ \\
\hline & Fino de Carvão & $2,06^{\mathrm{ABa}}$ & $2,23^{\mathrm{Ba}}$ & $2,02^{\mathrm{Aa}^{\mathrm{a}}}$ \\
\hline
\end{tabular}

Médias seguidas pela mesma letra maiúscula, na coluna, e minúscula, na linha, não diferem estatisticamente a $5 \%$ de probabilidade pelo teste de Tukey;Valores entre parênteses indicam o coeficiente de variação $(\%)$.

\section{Discussão}

Durante o processo de briquetagem, o teor de umidade pode facilitar a solubilização das fibras da madeira, mas, em grande quantidade, pode vir a reduzir a densidade e a resistência mecânica do produto final. $\mathrm{O}$ nível de tolerância do teor de umidade em um briquete é entre 8 e $12 \%$ dependendo da natureza do material. Acima destes níveis, a eficiência térmica é afetada negativamente assim como a taxa de queima, pois mais energia será usada para eliminar a umidade. Alta umidade pode ainda tornar o briquete susceptível ao ataque de fungos e outros microorganismos, como insetos e bactérias (Onukak et al. 2017).

Os briquetes produzidos com resíduos e baixa pressão apresentaram valores médios de teores de umidade abaixo do limite de tolerância. Os baixos teores de umidade podem ser explicados parcialmente pela capacidade absortiva do material aglomerante que sofreu previamente o processo de polpação kraft (Dias Júnior et al. 2016). Os briquetes produzidos também apresentaram teores de umidade inferiores aos apresentados na literatura e produzidos com produtos similares. Martins et al. (2016) produziram briquetes de finos de carvão aglutinados com resíduos celulósicos e apresentaram umidade média de 10,87\%. Valores médios muito semelhantes $(10,79 \%)$ também foram determinados por Dias Júnior et al. (2016) que utilizaram proporções iguais de resíduo celulósico e moinha de carvão vegetal. Por sua vez, Shyamalee et al. (2015) produziram briquetes com serragem de madeira e aglutinado com polpa de celulose com umidade de $20 \%$.

Um alto valor de massa específica é característica considerada desejável para briquetes, sendo o valor mínimo de 0,6 g.cm-3 recomendado para um transporte e armazenamento do produto mais eficiente, contudo está variável é diretamente correlacionada com a pressão exercida no processo de fabricação do produto (Oladeji e Enweremadu 2012). Considerando o método de densificação utilizado, os briquetes apresentaram valores médios de massa específica semelhantes aos relatados na literatura para produção com baixa pressão. Chin e Siddiqui (2000) apresentaram briquetes de serragem em torno de $0,35 \mathrm{~g} \mathrm{~cm}-$
3. Oladeji (2012) produziu briquetes com diversos resíduos agrícolas com densidades entre 0,24 a $0,51 \quad \mathrm{~g} . \mathrm{cm}^{-3}$. Shy amalee et al. (2015) utilizaram o mesmo tipo de prensa usada nesta pesquisa e produziram briquetes de serragem aglutinados com papel com valores médios de massa específica de $0,29 \mathrm{~g} \cdot \mathrm{cm}^{-3}$.

Em relação a química imediata, é importante se avaliar o teor de materiais voláteis pois se relaciona diretamente com a queima no processo de carbonização. Quanto maior o teor de materiais voláteis, mais rápido é a queima (Oliveira et al. 2017). Em briquetes produzidos com resíduos celulósicos, o teor de materiais voláteis tende a aumentar com o aumento da proporção de aglomerante na composição (Martins et al. 2016). Este comportamento não pode ser observado neste trabalho, pois os valores médios dos teores de materiais voláteis dos briquetes produzidos com finos de carvão foram semelhantes aos apresentados por Sotannde et al. (2010) para briquetes de carvão aglutinados com materiais nãocelulósicos, que apresentaram valores médios entre 10 e $13 \%$.

Contudo, os briquetes com serragem em sua composição aglutinados com papelão e papel jornal apresentaram valores considerados baixos. Materiais com baixo teor de voláteis resultam em combustões lentas que podem ser consideradas incompletas e levar a liberação significante de fumaça e gases tóxicos (Akowuah et al. 2012).

Cinzas influenciam a transferência de calor na superfície do material combustível, assim como na difusão de oxigênio durante a combustão. Como as cinzas não queimam, briquetes com baixos teores são mais recomendados (Akowuah et al. 2012). Recomenda-se que briquetes sejam compostos por materiais com teor de cinzas preferencialmente abaixo de $4 \%$ (Chen et al. 2009). A maior parte dos briquetes produzidos atenderam este requisito, com exceção daqueles feitos com finos de carvão aglutinados com papel de impressão $(8,13 \%)$ ou papelão $(4,50 \%)$ e os que utilizaram a mistura serragem e carvão e foram aglutinados com papel de impressão (5,38 \%). Porém, mesmo estes apresentaram valores médios inferiores aos produzidos por Martins et al. (2016) ao utilizar de 40 a $45 \%$ de aglomerante celulósico.

O teor de carbono fixo também está diretamente correlacionado com a quantidade de material celulósico utilizado na composição dos briquetes (Martins et al. 2016). Altos teores de carbono fixo indicam a geração de maior calor durante a combustão, pois o carbono reage com o oxigênio e libera calor. Em briquetes produzidos apenas com papel reciclado, foi encontrado um valor médio de $8,89 \%$, considerado baixo em relação a outros materiais combustíveis ou lenha (Tamilvanan 2013). E embora o material aglutinante usado apresente baixa porcentagem de carbono fixo, os briquetes produzidos com misturas de serragem e finos de carvão apresentaram valores médios superiores a briquetes relatados na literatura que utilizaram outros aglutinantes e em menor proporções, como por exemplo, valores entre aproximadamente 60 e $77 \%$ apresentados por Pereira et al. (2009) ou 65,4 e 66,5\% apresentados por Donato et al. (2015).

O poder calorífico é a propriedade mais importante na determinação de eficiência de um briquete. Ele indica a quantidade de combustível necessária para gerar uma determinada quantidade de energia (Sotannde et al. 2010). Altos valores de poder calorífico geralmente estão associados a altos valores de teor de carbono e a condições do processo de formação do briquete, como temperatura e

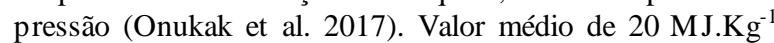
encontrado em briquetes de carvão vegetal ou serragem 
podem gerar energia suficiente para cozinhar domesticamente ou abastecer fornos industriais de pequena escala (Akowuah et al. 2012). Todos os briquetes produzidos e aglomerados com resíduos neste estudo apresentaram valores acima de $30 \mathrm{MJ} \cdot \mathrm{Kg}^{-1}$. Estes valores também são superiores ao valor médio da celulose (19 $\mathrm{MJ} . \mathrm{Kg}^{-1}$ ), material usado como aglomerante (Gonçalves et al. 2009). Os valores médios encontrados nesta pesquisa também foram superiores aos encontrados por Shy amalee et al. (2015) para briquetes de serragem com 30\% de papel reciclado como aglomerante e também prensado com baixa pressão (23 MJ.Kg $\left.{ }^{-1}\right)$.

Como regra, combustíveis que liberam quantidade suficiente de energia (calor) durante a combustão, mas que consume muita massa para gerar essa energia, apresentam baixos valores de ICOM (Dias Júnior et al. 2015). Os briquetes produzidos apresentaram valores médios de ICOM superior aos apresentados por Ramos e Paula et al. (2011) para briquetes de serragem ou carvão $(0,52$ e 0,56, respectivamente).

\section{Conclusão}

Com base nos resultados das propriedades químicas dos briquetes produzidos com resíduos de marcenaria e de carvoarias aglomerados com resíduos de tipo de papéis, os produtos possuem potencial para servir como fonte de energia para comunidades de baixa renda pois são compostos de produtos de fácil acesso e a metodologia de prensagem semi-manual e de baixo custo. Sendo que, dentre os materiais testados, recomenda-se o uso da mistura de serragem de Maçaranduba (Manilkara sp) com finos de carvão em partes iguais e aglomerados com papelão ou papel jornal.

\section{Referências}

Akowuah JO, Kemausuor F, Mitchual SJ (2012) Physicochemical characteristics and market potential of sawdust charcoal briquette. International Journal of Energy and Environmental Engineering. 3(20):1-6. doi: 10.1186/22516832-3-20

American Society for Testing and Materials. ASTM D $1762-$ 84 (1990): Standard method for chemical analy sis of wood charcoal. Philadelphia, USA.

Chen L, Xing L, Han L. (2009) Renewable energy from agro-residues in China: solid biofuels and biomass briquetting technology. Renewable and Sustainable Energy Reviews. 13(9):2689-2695. doi 10.1016/j.rser.2009.06.025

Chin OC, Siddiqui KM (2000) Characteristics of some biomass briquettes prepared under modest die pressures. Biomass and Bioenergy. 18(3):223-228. doi: 10.1016/S0961-9534(99)00084-7

Cruz BCC, Silva DA, Oliveira AS, Santos AB (2016) Produção de briquetes de resíduos agrícolas e de serraria, acrescido de resina de breu amarelo. Revista Brasileira de Energias Renováveis. 5(2):238-252.

Dias Júnior AF, Brito JO, Andrade CR (2015) Granulometric influence on the combustion of charcoal for barbecue. Revista Árvore. 39(6): 1127-1133. doi: 10.1590/0100-67622015000600016.

Dias Júnior AF, Andrade AM, Carvalho AM, Benício EL, Brito JO (2016) Produção de briquetes de moinha de carvão vegetal e resíduos lignocelulósicos visando uso bioenergético. Scientia Forestalis. 44(110):453-462. doi:10.18671/scifor.v44n110.18

Donato DB, Silva CMS, Magalhães MA, Araújo Júnior CA, Carneiro ACO, Vital BR (2015) Propriedades de briquetes obtidos de finos de carvão vegetal. Ciência da Madeira. 6(2):107-111. doi. 10.12953/2177-6830/rcm.v6n2p107111

Fuwape JA (1996) Effects of carbonization temperature on charcoal from some tropical trees. Bioresource technology. 57(1): 91-94.

Gonçalves JE, Sartori MMP, Leão AL (2009) Energia de briquetes produzidos com rejeitos de resíduos sólidos urbanos e madeira de Eucalyptus grandis. Revista Brasileira de Engenharia Agrícola e Ambiental. 13(5):657661. doi: $10.1590 / \mathrm{S} 1415-43662009000500021$.

Machado MF, Gomes LJ, Mello AA (2010) Caracterização do consumo de lenha pela atividade de cerâmica no estado de Sergipe. Floresta. 40(3):507-514. doi 10.5380/rf.v40i3.18912

Magalhães JM, Moreira AP (2011) Potencial e participação das florestas na matriz energética. Pesquisa Florestal Brasileira. 31(68):362-372. doi: 10.4336/2011.pbf.31.68.363

Martins MP, Benício EL, Dias Júnior AF, Almeida RB, Carvalho AM, Yamaji FM (2016) Produção e avaliação de briquetes de finos de carvão vegetal compactados com resíduo celulósico proveniente da indústria de papel e celulose. Revista Árvore. 40(1): 173-180, 2016. doi: 10.1590/0100-67622016000100019

Oladeji JT (2012) Comparative study of briquetting of few selected agro-residues commonly found in Nigeria. The Pacific Journal of Science and Technology. 13(2): 80-86

Oladeji JT, Enweremadu CC (2012) The effect of some processing parameters on physical and densification characteristics of corncob briquettes. International Journal of Energy Engineering. 2(1):22-27. doi: 10.5923/j.ijee.20120201.04

Oliveira LH, Barbosa PVG, Lima PAF, Yamaji FM, Sette Júnior CR (2017) Aproveitamento de resíduos madeireiros de Pinus sp. com diferentes granulometrias para a produção de briquetes. Revista de Ciências Agrárias. 40(3): 683-691. doi: 10.19084/RCA17010

Onukak IE, Mohammed-Dabo IA, Ameh AO, Okuduwa SIR, Fasany a OO (2017) Production and characterization of biomass briquettes from tannery solid waste. Recycling. 2(17):1-19. doi:10.3390/recy cling2040017

Pereira FA, Carneiro ACO, Vital BR, Lúcia RMD, Patrício Júnior W, Bianche JJ (2009) Propriedades físico-químicas de briquetes aglutinados com adesivo de silicato de sódio. Floresta e Ambiente. 16(1):23-29.

Ramos e Paula LE, Trugilho PF, Rezende RN, Assis CO, Baliza ERA (2011) Produção e avaliação de briquetes de resíduos lignocelulósicos. Pesquisa Florestal Brasileira. 31(66):103-112. doi: 10.4336/2011.pfb.31.66.103

Riegelhaupt EM, Pareyn FGC (2010). A questão energética. In: Gariglio MA, Sampaio EVSB, Cestaro LA, Kagey ama 
PY (org) Uso sustentável e conservação dos recursos florestais da caatinga. (2.ed.). Brasília: Serviço Florestal Brasileiro. p.65-75.

Shy amalee D, Amarasinghe ADUS, Senanayaka NS (2015) Evaluation of different binding materials in forming biomass briquettes with saw dust. International Journal of Scientific and Researcg Publications. 5(3): 1-8. doi: 10.29322

Sotannde OA, Oluyege AO, Abah GB (2010) Physical and combustion properties of charcoal briquettes from neem wood residues. International Agrophysics. 24(2): 189-194, 2010.

Souza GO, Castro VG, Guimarães PP, Freitas NWN (2018) Avaliação da qualidade da madeira comercializada no município de Mossoró, RN - um estudo de caso. Ciência da Madeira. 9(2):62-70. doi:10.12953/21776830/rcm.v9n2p62-70

Tamilvanan A (2013) Preparation of biomass briquettes using various agro-residues and waste paper. Journal of Biofuels. 4(2):47-55. doi:10.5958/j.0976-4763.4.2.006

Rezma S, Birot M, Hafiane A, Deleuze H (2017) Phy sically activated microporous carbon from a new biomass source: Date palm petioles. Comptes Rendus Chimie, 20(9-10): 881-887. doi: 10.1016/j.crci.2017.05.003. 